\title{
PERCEPÇÕES, SENTIDOS E SENSAÇÕES DE PROFESSORAS DA EDUCAÇÃO INFANTIL: ALGUNS ATRAVESSAMENTOS
}

\section{PERCEPTIONS, SENSES AND FEELS THROUGH THE TEACHER IN CHILD EDUCATION: SOME CROSSINGS}

\author{
CHISTÉ, Bianca Santos ${ }^{1}$ \\ SOUZA, Catiane Monteiro Pacheco ${ }^{2}$
}

\begin{abstract}
RESUMO
Este artigo apresenta discussões provocadas durante uma pesquisa desenvolvida junto ao PIBIC em 2017/2018, que teve como objetivo geral investigar quais percepções, sentidos e sensações atravessam professoras na educação infantil. Metodologicamente a pesquisa foi realizada com professoras que atuam em creches e pré-escolas de duas instituições de educação infantil, em Rolim de Moura, RO. Fundamentadas em Ribeiro; Souza e Sampaio (2018), optamos pela conversa como metodologia de pesquisa, na qual se apresentou como potência na pesquisa com professoras, pois abriu espaço para aproximações, cumplicidades, afinidades, enfim, intimidades. Para nortear as outras discussões nos amparamos nos estudos de Freire (1989), Gallo (2010), Fernandes e Hermelino (2012), Rocha (2015) entre outros. Os olhares e narrativas das professoras nos apresentam um "torna-se professora em movimentos e exercício permanente com as crianças", além de indicarem que a educação infantil é o lugar de experimentação, de sensações e de percepções.
\end{abstract}

PalaVras-chave: Infância; Pesquisa; Docência; Prática; Experiência.

\section{ABSTRACT}

This article addresses discussions conducted during a research developed in 2017/2018, whose general objective was to investigate which perceptions, senses and sensations are felt by preschool teachers. Methodologically, the research was conducted with teachers who worked in kindergartens and preschools at two institutions in Rolim de Moura, State of Rondônia. Based on Ribeiro; Souza and Sampaio (2018) we choose to use conversation as a research method, which showed itself as a powerful tool as it opened up for approximations, complicity, affinities and, in short, intimacy. To guide other discussions, we utilized studies by Freire (1989), Gallo (2010), Fernandes e Hermelino (2012), Rocha (2015) among others. The looks and narratives of the teachers point out that one becomes a teacher in movements and permanent exercise with the children, besides indicating that early childhood education is the place for experimentation, sensations and perceptions.

\footnotetext{
${ }^{1}$ Universidade Federal de Rondônia (UNIR) / Departamento de Educação. Rolim de Moura, RO, Brasil. ORCID: https://orcid.org/0000-0002-1962-0256 e-mail: bianca@unir.br

2 Universidade Federal de Rondônia (UNIR). Rolim de Moura, RO, Brasil. e-mail: catianemonteiropacheco@gmail.com
} 
DOI: $10.12957 / \mathrm{e}-\mathrm{mosaicos} .2020 .42516$

KeYworDS: Childhood; Search; Teaching; Practice; Experience

\section{CAMINHO TÊNUE do PROFESSORANDO}

Ao nos aventuramos pelos incertos caminhos de pesquisar com crianças, com infância e com a educação infantil muitas inquietudes emergem. Entre elas, questões direcionadas também às professoras da infância: $O$ que é ser professora? De que maneira nos tornamos professoras de crianças sem subtrairmos a infância? Como lidar com as crianças, ensinando "conhecimentos escolares" sem considerá-las a partir da falta e da ausência? Que caminhos seguir escapando da escolarização perene que adentra os espaços da educação infantil? Quando nos colocamos na condição de ouvidoras de professoras que atuam com crianças? O que as atravessam e as mobilizam nas vivências diárias com as pequenas e os pequenos? O que dizem sobre o mundo e sobre suas experiências educativas na educação infantil?

Quando nos colocamos a ouvir ou a conversar com professoras, nossa escuta ou nossa conversa, muitas vezes, já é fabricada segundo uma concepção identitária e categórica do que é ser professora de criança. Parece que estamos sempre ’à espreita, aguardando respostas que nos conduzem a dizermos sobre elas o que é ser ou não professora. Até mesmo em pesquisas as perguntas elaboradas previamente para uma entrevista, muitas vezes têm uma intenção de conduzir as respostas, ou seja, levar as entrevistadas a responderem o que queremos ouvir.

Como então escapar disso em uma pesquisa que tem como interesse investigar quais percepções, sentidos e sensações atravessam as professoras que atuam na educação infantil? Quais linhas de fuga podemos traçar para buscar indícios sobre o que as professoras pensam de suas práticas educativas com crianças? Que metodologia de pesquisa podemos fazer uso, que rompa com as previsões, com as confirmações de certezas, e se abra ao encontro com outro, que produza aproximações e experimentações da palavra e da vida partilhada?

Optamos então, pela conversa como metodologia de pesquisa, tendo em vista que ela abre caminhos para aproximações, intimidade, confidencialidade, possibilitando que outros assuntos, outras temáticas, outros saberes possam ser mobilizados. Nos colocando ainda na condição de ouvir as professoras, seus desejos, anseios, medos, alegrias, angústias. Para Ribeiro Souza e Sampaio (2018, p. 19) conversar é

[...] encontrar com o outro, imbuídos de uma questão comum, tratando-se de uma metodologia da presença e da escuta, o que implica numa estética e numa ética outras que nos levam a pesquisa compartilhadamente, nas interações.

A pesquisa com crianças e infância tem nos possibilitado então, pensar outros modos de fazer pesquisa. A ideia da conversa com as professoras, e não a entrevista que comumente é realizada, surgiu a partir das seguintes inquietações: O que pode uma conversa? O que provoca uma conversa? Essa opção metodológica se apresentou enquanto potência na pesquisa com professoras, pois abriu espaço para aproximações, 
DOI: $10.12957 / \mathrm{e}-\mathrm{mosaicos} .2020 .42516$

cumplicidade, afinidades, interioridades, enfim, intimidade. A intimidade cria laços e vínculos, sustenta relações, gera um elo, um contato, uma tensão, um movimento. Propicia um caminho possível para conhecer o outro, os seres, as coisas, o mundo. Entre afetos e sensações, a intimidade permite que você toque com os olhos, com a pele, com as mãos, com o gesto, com o corpo, com as palavras desengavetadas. De acordo com Ribeiro Souza e Sampaio (2018, p. 165)

Antes de verbo, conversar é uma postura, um posicionamento, uma abertura: ao encontro, ao diálogo. [...] A conversa é um acontecimento, uma irrupção: aquilo que acontece borrando os contornos do esperado, desarrumando o ordenado, extrapolando o pensado. É a desestabilização do ser; a ratificação do sendo.

Acreditamos que ouvir as professoras da infância é uma possibilidade para traçarmos um caminho em direção ao rompimento da inércia, do anulamento, da repetição escolar e dos tempos e espaços emparedados e policiados. A tomada da palavra pelas crianças e pelas professoras na educação infantil seria um acontecimento político, como preconiza Gallo (2010). Dessa forma, para que isso aconteça é preciso e-ducar o olhar, não no sentido de educare (ensinar), mas de e-ducere (conduzir para fora), libertar nossa visão das questões ligadas à educação, à própria instrução, e ao ser professor de criança.

A composição da docência na educação infantil que dialoga com a infância como centro de suas experiências educativas tende a ser um contraponto ou um escape à ordem homogeneizadora. Uma docência a partir das crianças e da infância potencializa uma formação docente que esteja pautada nas diferenças, não se limitando a uma única linguagem, colocando em debate uma forma não escolar na educação infantil.

Tornar-se professora de criança exige mudança, pois as ideias de tempo e de verdade não são as mesmas quando estamos diante das crianças; o mundo não é o mesmo quando olhamos para tantos outros mundos inventados por elas. Como voltar a memória e os pensamentos para um tempo não mais vivido? Como ouvir o que não é mais ouvido? Como ver o que não é mais visto? Se pensarmos infância como experiência, como condição humana, como aprendemos com Agamben (2005), somos atravessados pela infância, pela nossa, das crianças e do próprio mundo.

É diante dessa infância que nos atravessa, que nossas verdades e concepções são estremecidas. São as inquietações e problematizações disparadas que podem trazer leveza de pensamento, abertura para novas ideias, transcendência de ser, e entendimento do caminho que está sendo criado, pois "é justamente nas contradições que podemos pensar, se é que pensar tem a ver com criar e não apenas reproduzir o já pensado". (KOHAN, 2007, p.88)

Assim, tornar-se professora de crianças inicia-se no encontro com elas, nos afetos produzidos, no rompimento de verdades supostamente imutáveis, no olhar sensível mobilizado, na construção permanentemente movente e imanente de si, como aponta Rocha (2015, p.4) 
DOI: $10.12957 / \mathrm{e}-\mathrm{mosaicos} .2020 .42516$

Assim, a fórmula do tornar-se quem se é não pode ser compreendida como o percurso que conduz à atualização de uma essência. Ela não é da ordem de um imperativo ou de um projeto, que deveria guiar a vida como um princípio transcendente, mas é antes a descrição de um processo inteiramente imanente.

Dessa forma, outras educações, no plural, podem ser pensadas, para e com a infância, a partir do que ela tem e não do que lhe falta: como presença, e não como ausência; como afirmação, e não como negação; como força, e não como "incapacidade", como aponta Kohan (2007, p. 101). Pensar a infância e a criança a fim de enfatizar seus saberes, levando em consideração suas singularidades, e peculiaridades pode ser uma ação pedagógica de emancipação, de valorização da criança, de contemplação do ser, de respeito, de imanência. Segundo Kohan (2007, p.97)

Talvez possamos pensar de novo um outro lugar minoritário, molecular, para a infância, na espacialidade molar e concêntrica da escola; talvez queiramos promover outras potências de vida infantil, outros movimentos e linhas nesse território tão maltratado, descuidado e desconsiderado que é a escola.

Desse modo, indagações nos seguem: o que as professoras de crianças dizem de si e do mundo? Que afetos lhes atravessam nas relações com as crianças, com a escola, com a vida? Que caminhos as conversas com elas disparam? Que sentidos suas vivências e experiências na educação infantil provocam em si e no outro? Perguntas convite. Convite à leitura deste texto cujo desejo é partilhar o que conversas com professoras provocaram e nos levaram a pensar. $O$ estar junto, inerente à etimologia da palavra conversar, possibilitou conhecer diferentes maneiras de fazeres, de pensar a educação infantil, e entender que as reflexões a partir das experiências partilhadas durante esses momentos podem delinear caminhos de uma educação de qualidade, que respeita o espaço-tempo da criança, potencializando os meios e as ações dos que estão envolvidos na educação da infância.

\section{O ESPAÇO NA EdUCAÇÃo INFANTIL, E A PRÁTICA DA PROFESSORA 3 , PORQUE}

"[...] a educação infantil é esse espaço da experimentação..." 4

É a partir da inquietação de "quais percepções, sentidos e sensações de atravessam professoras que atuam com educação infantil no município de Rolim de Moura" que esse estudo se constitue. Professoras da educação infantil, no segundo semestre de 2017 e primeiro semestre de 2018, foram convidadas a uma conversa

3 Os títulos são compostos com fragmentos de falas extraídas das conversas com as professoras no contexto da pesquisa. Optamos por usar a palavra no feminino, visto que o universo docente da educação infantil é composto, em sua maioria, por mulheres.

4 Professora Fagda. 
DOI: $10.12957 / \mathrm{e}-\mathrm{mosaicos} .2020 .42516$

para falar um pouco da vida de ser professora de criança. As conversas circularam durante três encontros, compostos por 03 professoras, totalizando 09 docentes participantes na pesquisa.

Para disparar a conversa sugerimos às professoras que exibissem imagens ${ }^{5}$ produzidas por elas nos espaços da educação infantil, pois, como Gagnebin (2004, p. 80) aponta, as imagens são capazes de reter o fluxo do tempo "na intensidade de uma vibração". Além disso, carregam consigo e movimentam pensamentos, pois nos provocam a pensar: um real visível, que pode estar diante dos olhos; um real invisível que está para além do olho, uma invenção de vida, um desejo, um anseio, uma faísca de imaginário. Imagens que podem ser um convite ao exercício dos olhos, dos perceptos, como forma de resistência, como pensamentos das regularidades, das formas. Imagens que, de alguma maneira, atravessam e afetam quem as capturam e quem as olham. Ou seja, trazer as imagens para a conversa movimentou a experiência de se pensar o ainda não pensado, o ainda não dito, o ainda não vivido.

Imagens, conversas, falas ${ }^{6}$ : olhares, experiências, vivências, afetos, sentidos, percepções. Cada pessoa apresenta em sua constituição, especificidades que a torna singular. As ideias de tempo, de sentidos, de espaço e de percepção são a identidade que difere em cada ser humano. Se existir um aprofundamento no campo das percepções, o que se pode notar é que o que difere o mesmo espaço para duas pessoas ou mais é o olhar que cada uma apresenta em relação a ele. Para Rocha (2015, p. 7)

[...] não é da ordem da introspecção, mas dos agenciamentos: tornamo-nos quem somos não por manifestar uma essência dada desde sempre, mas pelo encontro com a alteridade, pela forma como assimilamos as experiências, como assimilamos a diferença, como nos transformamos no embate com as circunstâncias

É a partir desse olhar que este ponto foi criado e será discutido aqui. O mundo percebido pelas crianças é diferente do mundo dos adultos, não somente por uma questão cronológica e espacial. Nesse caso, fragmentos de vivências, de olhares, de experiências de professoras, no espaço da educação infantil, em um município em Rolim de Moura, RO, nos colocam a pensar elementos que constituem a docência na educação infantil.

Para as crianças, o tempo (que ainda não passou) é diferente do tempo do adulto. As obrigações diárias, as percepções acerca dos horários e do trabalho não existem. É aí que se encontra o movimento para a observação e o descobrimento. Quando não há pressa, há tempo, e quando há tempo, há possibilidades de aprendizado.

5 Optamos por não exibir, nesse trabalho, imagens produzidas pelas professoras, pois não tivemos acesso às autorizações dos pais e/ou responsáveis.

6 Declaramos que temos direitos de exibição das falas das professoras produzidas no contexto de pesquisa. 
DOI: $10.12957 /$ e-mosaicos.2020.42516

Tudo para elas é novidade, uma borboleta já chama atenção, um formigueiro [...], nossa o dia do formigueiro foi a festa, porque esse formigueiro é bem em frente da minha sala então quando fomos para o café da manhã a primeira coisa que elas viram foi esse formigueiro, então eu tinha todo planejamento para aquele dia, e o formigueiro não estava no planejamento. Tem aquela história, havia um não sei o que lá no meio do caminho? No meio do caminho havia um formigueiro (Professora Goia).

O que se percebe, a partir dessa experiência, é que as crianças se interessam em explorar os meios em que elas vivem. Nesse caso o planejamento da professora Goia foi construído juntamente e a partir das crianças; com um olhar sensível sobre as crianças e sobre o mundo e aberta ao acontecimento e ao inesperado, isso pode potencializar uma descoberta das pequenas. De acordo com Freire $(1989$, p.33)

Não será demasiado insistir na importância, para as crianças, de se sentirem autoras, com a professora, da programação de nossa atividade. Por outro lado, a importância também de perceberem o que estão fazendo e o que deixam de fazer na programação geral. É exatamente esse tipo de vivência que leva a reprogramar a programação já feita.

Outro ponto para discussão a respeito do espaço e da prática da professora em relação às novas formas de aprender é a potencialização dos lugares que fazem parte do convívio das crianças. Uma rua antiga, uma grama mal cortada, uma casa de cupins, uma pedra grande, tudo isso se transforma em espaço de aprender, como relata a professora Delilla "[...] Aquela caverna né, e a questão também daquela caverna que aí surgiu um tanto de assunto, eles perguntaram se lá existiu dinossauro, qual homem que colocou aquela pedra lá".

Além dos espaços presentes na vida e no cotidiano das crianças, outros potencializadores de imaginação podem ser encontrados. Conhecer o que ainda não se conhecia, aprender o que não se sabia, sentir o que não se sentia, ouvir o que não se ouvia faz parte do processo da descoberta, e, mais uma vez, esse momento pode ser pensado pelas professoras.

Nós fomos no Gaia, e esse dia já tinha começado as chuvas então tinha água, muita coisa, gente, moleque subiu em árvore, ficou pendurado, assim... nossa eles fizeram de tudo nesse lugar. Você olhava assim, subia na pedra, o piá estava agarrado, eu tirei uma foto e mandei para o pai dele, e falei assim: olha o que seu filho está fazendo, mas não se preocupa não, eu estou aqui em baixo pra segurar, a mãe falou assim: não professora não se preocupa não eu já estou acostumada. (Professora Herena). 
DOI: $10.12957 / \mathrm{e}-\mathrm{mosaicos} .2020 .42516$

É a partir de então que os estudos da professora acerca da infância se apresentam como fundamentais nas relações com a educação infantil, é assim que podemos entender que "a criança pensa, agindo concretamente sobre o mundo. Ela opera, pensa a realidade transformando-a, e cada vez mais este pensar vai deixando de se apoiar no concreto. A criança vai interiorizando, abstraindo suas ações sobre a realidade" (FREIRE, 1989, p.29), e a professora potencializando essa relação. Isso pode ser observado na fala da professora Delilla

Depois levei eles lá pra ver as árvores, tocar as frutinhas dessa mesma árvore e a outra que estava morta, gente eles pegavam na casca a diferença da casca da árvore morta para a outra árvore, entendeu? E então essa coisa toda e todos queriam saber porque que a árvore morreu, então assim é interessante você ter essa área para trabalhar junto com eles [...].

Mesmo o sistema educacional estabelecendo métodos, normas, um currículo (que muitas vezes mais fecha possibilidades) para o desenvolvimento da criança, as invenções e as possibilidades de descobrimento são importantíssimas para as elas, como menciona a professora Ebe "[...] eu comecei a perceber, a gente prende demais as crianças. Aquelas quatro paredes ali de ficar naquelas cadeirinhas, então quando você sai também, não dispersa desde que elas estejam fazendo uma coisa que elas gostam."

Quando as atividades, por mais cotidianas que sejam, são pensadas; quando há potencialização nas atividades exercidas pelas crianças; quando há uma valorização no tempo e no espaço que constitui a infância, o tempo flui como água corrente, e as relações entre a professora e as crianças na educação infantil se transformam cada vez mais em riquezas de saber. Como refere a professora Ebe

Tudo que a gente faz dentro da educação infantil se você quiser você coloca objetivo em tudo, em tudo tem objetivo, a ludicidade, a coordenação motora, mas quando você observa que além da ludicidade além de aprender brincando [...] que ela fez por prazer [...].

É aqui que se pode diferenciar a cultura escolar, que é entendida "a partir das normas, rotinas e ritos próprios da escola enquanto instituição social, como um elemento estruturante do cotidiano de adultos e crianças[...]" (FERNANDES e HERMELINO, 2012, p.5) e o momento de interação existente entre professoras e crianças na educação infantil, pois "a subjetividade é compreendida aqui como uma noção distinta da individualidade, por não ser fechada em si mesma, mas por ser atravessada e composta no e pelo social" (SILVA e SANTOS, 2011, p.3).

Portanto, ser professora de criança, de acordo com professora Beres "é desafiar-se a si mesma", é entender que trabalhar com espaços tão distintos exige uma concepção de subjetividade que não acontece involuntariamente, mas com o exercício da reflexão a partir da prática. Assim, pode-se saber que o mundo antes visto 
DOI: $10.12957 / \mathrm{e}-\mathrm{mosaicos} .2020 .42516$

com olhos adultos se expandirá em detalhes, e o olhar da criança se abrirá para novas descobertas. De acordo com Fernandes e Hermelino (2012, p.3).

[...] podemos ver apenas algumas coisas, outras nos fogem da visão, da nossa percepção, e podemos considerar que as crianças conseguem ver muitas coisas que nos escapam, as crianças funcionam como o excedente de visão, deixando pistas em suas falas, suas relações cotidianas, suas opiniões e reflexões sobre as tarefas e solicitações escolares.

Uma das reflexões que emergiu durante as conversas com as professoras possibilitou vermos, pelos olhares delas, o mundo das crianças: repleto de grandezas e miudezas, de claridades e sombras, de cores quentes e frias, ou seja, habitado pela infância, como relata a professora Ebe

[...] eu já tive boi rosa, boi azul, boi verde, então assim, o boi é da criança. Por que que o boi dela não pode ser daquela cor se ela quiser? Se eu quiser ter um também, cada um pinta da cor que quiser. A gente tem que respeitar o que a criança faz, e não assim: a criança as vezes pega um determinado desenho, o que que a gente espera, que aquela criança vai lá e que segue a linha tudo certinho, então não, as minhas crianças [...] pegam e fazem assim (exemplo riscando), aí quando algum determinado professor vai lá, aí eu chego lá, tá tudo tão certinho, eu falo: meu Deus do céu eu não tô vendo, porque a criança comigo [...] não está fazendo do mesmo jeito.

Olhar para a criança de maneira sensível, enxergá-la em sua existência presente, "priorizar o que a criança faz, considerar o que a criança faz", como assevera a professora Ebe, é fundamental em uma educação na infância, pois é na escola também que as crianças fazem o papel de socializadoras e conhecedoras umas das outras, "expressando seu modo de agir, de relacionarem-se, seus hábitos, crenças, valores; cultura inscrita nas rotinas, ritmos e ritos, na linguagem, no imaginário" (FERNANDES e HERMELINO, 2012, p.5). A professora Beres acrescenta que

É difícil para as crianças chegarem na educação infantil sem os pais, muitas deles pela primeira vez, e experimentar (como a Diane disse), novas relações e é um processo de humanização delas que está ali, então aquele olhar desconfiado meio assim: será que vai ser meu amigo? Será que não? Eu estou aqui na minha zona de conforto e você veio aqui e tal, mas ele está tranquilo na zona de conforto dele, tão pequenos e eles já tem essa atitude de testar mesmo essas relações: será que vai ser meu amigo? Será que não? E procurar um ambiente que se sintam mais seguros, e por outro lado, olha a criança olha para o colega, abaixa para falar com ele. É uma relação de convite a fazer amizade, de mostrar confiança, de confiabilidade [...]. 
DOI: $10.12957 / \mathrm{e}-\mathrm{mosaicos} .2020 .42516$

O exercício de olhar e ver pode ser capaz de ensinar que as crianças produzem conhecimento nas relações e conexões que estabelecem com o mundo. É importante compreendermos que professoras e crianças (também as merendeiras, as zeladoras, o porteiro, as gestoras) fazem parte do processo, de conhecer o mundo e aprender com elas. As professoras Beres e Ebe observam que

Às vezes nem é a atividade as vezes a máxima do dia as vezes nem foi a atividade, as vezes foi uma relação na hora do lanche do partilhar, em fim da conversa das relações que teve para além da atividade, coisas que geralmente por exemplo, os brinquedos as vezes estão distribuídos no momento em que os pais estão vindo buscar as crianças, aí não causa aquele tumulto, na hora que os pais vir buscarem, no caso os brinquedos da turma, quando os pais estão chegando enfim, e geralmente é um momento que você acha que a aula já acabou, os pais estão vindo buscar falta vinte minutinhos, quinze minutinhos as vezes é nesse momento que elas estão testando as relações, de coisas que vão levar pelo resto da vida. (Professora Beres).

Porque o adulto tem afinidade com outro a gente tem com todo mundo no local de trabalho isso é mais uma questão de interesse uma questão de política, uma questão de ser adulto uma questão de se relacionar bem, porque você precisa disso, mas a gente não tem afinidade com todo mundo, a verdade é essa, e a as crianças não têm que ter com a gente porque são crianças. (Professora Ebe).

É a partir de então que se pode afirmar que as relações humanas são produzidas e também conhecidas a partir dos estudos da infância: os projetos de afinidade, a delicadeza com que há os primeiros contatos com amigos, a ideia de conhecer o novo e se conhecer a partir do novo é um movimento enriquecedor, até porque as crianças não são obrigadas a se engessar num mundo adulto para aprender, "não têm que aceitar" (Professora, Ebe) uma imposição sobre isso. Fernandes e Hermelino (2012, p.12) nos dizem que

Aceitar as incertezas é um movimento que nos permite ir rompendo com um pensamento de respostas simplistas, dicotômicas, buscando categorizações e classificações, no qual, o que não é classificável dentro dos critérios estabelecidos, foge ao padrão da 'normalidade', torna-se excluído.

Por fim, a partir do que a educação infantil apresenta, seja em coisas para pensar, experiências para se trocar, olhares para se abrir, pode se entender que a prática pedagógica, mesmo sendo pensada individualmente, deve ser construída assim: "nós estamos juntos nos conhecendo e descobrindo e conhecendo o mundo" (FREIRE, 1989, p.54). O contato com as crianças já é uma ação inovadora nesse meio, a coletividade é um caminho potente de ser percorrido quando o assunto é educação infantil. 
DOI: $10.12957 / \mathrm{e}-\mathrm{mosaicos} .2020 .42516$

\section{SENSAÇõES E PERCEPÇÕES QUE ATRAVESSAM A EdUCAÇÃo INFANTIL}

É evidente que as relações existentes em sala de aula, principalmente na Educação Infantil, estão presentes e atuantes no cotidiano de cada professora. Isso não acontece somente por estar se relacionando com crianças, mas porque é da natureza humana sentir e ser atravessado pelas coisas que rodeiam. Quando o trabalho foi pensado, a ideia de cercear ou não a infância surgiu dessas relações e dessa troca de sensações.

Construir uma pesquisa acerca da criança, das práticas com elas, do espaço e do tempo que constitui a infância e de uma educação não cerceadora desse lugar que constitui o ser criança, é desafiador. Paradigmas acerca da infância devem ser estremecidos e transformados e o olhar das pesquisadoras deve ser exercitado para que as coisas mais miúdas sejam consideradas. De acordo com Freire (1989, p.68)

[...] é na prática em que o professor não se coloca como dono exclusivo do que sabe, mas, pelo contrário, é através do que ele sabe que ele encaminha e sistematiza os dados observados na prática das crianças, para que elas próprias façam suas descobertas.

A priori, cabe entender que a ideia de experimentar é despretensiosa, sem pretensão num sentido de não preparar ninguém para a vida, mas fazer descobrir a vida que já existe, pois não está ligada a um modelo de adulto, e sim, valorizar as vivências das crianças, cada uma no seu tempo. É isso "que nos dá certeza de que a busca do conhecimento não é, para as crianças, preparação para nada, e sim vida aqui e agora" (FREIRE, 1989, p.50).

E viver cada momento da vida presente desenvolve nessa vivência uma série de sentimentos. Alguns deles serão destacados neste escrito para uma reflexão a respeito do viver a infância e com a infância, sem "subtraí-la" no exercício de ensinar as crianças e aprender com elas.

O primeiro sentimento a ser destacado aqui é o prazer. A terminologia é um tanto cotidiana quando se pensa nas mais variadas experiências que o ser humano apresenta, mas o prazer em sala de aula é algo que, muitas vezes, foge das concepções sobre a educação. Um exemplo da manifestação do prazer na educação infantil é a proposição das atividades lúdicas, como aponta a professora Amires, "a gente precisa ensinar de uma forma que brinque e ensine ao mesmo tempo".

Mas brincar não é o único propulsor dos prazeres que aprender na infância traz. O prazer da descoberta é um deles: "vale a pena abrir um parêntese aqui para falar da importância das descobertas das crianças" (FREIRE, 1989, p.45). Ora, o mundo, quando visto como novidade, é cheio de detalhes interessantes, e fomentar esse gosto por descobrir é se colocar na posição de quem deseja abrir os olhos para olhar com olhares de quem gosta de conhecer o novo. Em relação isso a professora Herena traz o seguinte relato: 
DOI: $10.12957 / \mathrm{e}-\mathrm{mosaicos} .2020 .42516$

A Léo levou galinha para elas tocarem, numa galinha, uma tartaruga, um jabuti para explicar a diferença, e um coelho. Então, elas tiveram esse contato também com animais, coisas que nós já havíamos trabalhado em sala, e que lá elas reforçaram de uma maneira diferente. A questão até mesmo da natureza das árvores, pedras, águas, o meio ambiente mesmo, quando você trabalha o meio ambiente, então ali é um jeito de dar uma fugidinha mesmo.

É evidente que as descobertas das crianças nessa experiência não se pautaram apenas no meio ambiente, mas também em várias outras questões sobre espaço, relações, curiosidades, além das concepções acerca da igualdade e a diferença, e do "lugar" de cada ser no mundo. Outrossim, descobrir o mundo prazerosamente é abrir espaço para imaginar e criar a partir do que já se conhece ou se vê. Observamos no relato da professora Delilla o inesperado e o imprevisível acontecendo:

[...] um dia apareceu uma coruja em cima [...] da grade da janela, nossa, aí [...] umas crianças, [...] chegaram em casa e falaram, elas relacionaram a coruja com bruxa, aí disse que tinha uma bruxa na escola que não sei o que, e que a bruxa... E no outro dia, os pais perguntando se alguém foi vestida de bruxa, porque ela falava muito dessa bruxa e de noite ela estava falando dessa bruxa, aí eu fui falando: não, foi a coruja.

O animal visto pelas crianças, nesse caso, abriu mão de sua existência comumente natural para se transformar em um personagem muito conhecido nos caminhos da Educação Infantil: a tão temida, mas tão interessante - Bruxa - que mesmo parecendo má, está relacionada aos mais variados assuntos pertinentes na vida das crianças: seja na convivência constante dela com crianças, no estranho protagonismo que as próprias crianças a colocam.

Mas como entender essa relação? Será que entender a infância é um ato de "rebeldia"? "Não é presunção de nossa parte até mesmo tentar fazê-lo?" (HAWKING, 2016, p.77). De fato, o exercício de viver a infância é algo fora dos planos de quem a estuda, como declara a professora Ebe: "nós não somos crianças", mas se permitir imaginar é um passo para que se conviva com as crianças sem deixar de acolher, afetar-se com o que elas nos apresentam.

Outro elemento, que também é da ordem da afetação que observamos e que faz parte do prazer da descoberta do mundo e dos espaços da educação infantil, é a empatia. É mais um "olho no olho", uma delicadeza que é desenvolvida em cada pessoa a partir de suas relações sociais, mas que acontece na existência e nas ações das crianças desde os primeiros contatos entre elas, como no caso de duas crianças se conhecendo, no qual uma estava começando a se adaptar, "ele ganhou um olhar desconfiado, mas ele está ali", como nos diz a professora Beres. Portanto, potencializar isso é respeitar a infância, 
DOI: $10.12957 / \mathrm{e}-\mathrm{mosaicos} .2020 .42516$

acho que o recado que as crianças nos dão é a delicadeza das relações [...] não é infantilizar a criança é deixar ela no seu momento certo, nem infantilizar e nem achar que é adulto em miniatura, é perceber que a criança está no momento certo, e nós não estamos na educação infantil para escolarizar a criança [...]. (Professora Beres).

Por conta disso, pensar na criança é querer fazer diferente. Os caminhos da educação infantil necessitam de pessoas que estejam dispostas a conhecer o novo, a se movimentar para inovações e experimentações, portanto, "faça movimentos, movimente-se, encontre as brechas para fazer as mudanças, para fazer as melhorias, se você pode fazer uma melhoria na vida de uma criança vai refletir no futuro dela", como afirma a professora Herena.

Encontrar os becos e as brechas, embora pareça ser assustador demais a ser pensado, se transforma em uma rede de possibilidades quando produzimos uma docência com as crianças e a infância. Estar ciente de que ser professora, assim como ser criança, não é algo circunscrito e determinado. Ou seja, é movimento de velocidades e intensidades, que possibilitam mudar realidades e potencializar o descobrimento de novas concepções. É saber que as práticas em sala de aula devem ser pensadas e refletidas constantemente. Nesse sentido, Fernandes e Hermelino $(2012$, p. 15) afirmam que

Considerar a professora como sujeito capaz de refletir e teorizar sobre sua prática, reconhecendo a escola como espaçotempo do cotidiano que para alguns é só o comum, o natural, o mesmo, embora desafiador, complexo, híbrido, em permanente construção, desconstrução e reconstrução, exigindo constante açãoreflexãoação.

Logo, "compreender o cotidiano da sala de aula como um encontro infinito de histórias individuais que se complementam, se embatem e se fundam, considerá-lo um espaço de possibilidades não determinadas" (FERNANDES; HERMELINO, 2012, p.9). As potencialidades disparadas produzem afetos, sensações e percepções, que estão presentes no ato de aprender, inventar e descobrir a si e o mundo. Observamos um pouco disso quando a professora Beres diz:

E você lidando com seres tão pequenos que estão aprendendo a lidar com as frustrações e ao mesmo tempo você é ensinada a lidar com as suas, é uma dialética ali, uma troca, não só uma troca, realmente uma dialética de você aprender a lidar com você e com o outro, e do outro que está lidando com ele e com você [...] que a educação infantil é para os fortes, porque ela exige de você, o que nem um outro segmento que eu experimentei até hoje exigiu emocionalmente.

Para professora Delilla ser professora de criança "é ter um olhar diferente [...] é ter esse olhar diferente para trabalhar emoções [...], poder mudar uma situação, 
DOI: $10.12957 / \mathrm{e}-\mathrm{mosaicos} .2020 .42516$

poder mudar é o destino de uma vida [...]", se transformar constantemente em professora de crianças é refletir, é praticar a partir do que já foi praticado, "Nesse sentido educador e educando, juntos repensam sua prática" (FREIRE, 1989, p.77).

Para isso, mesmo entendendo que a pedagogia "não é uma profissão que a gente ama o tempo todo, mas quando você junta o todo, você vê que é algo bom", como declara a professora Amires, o ponto que dá sustentação a toda uma ideia de inovação, conhecimento e constituição de si, é saber que há coisas para se fazer, há meios de se mudar, e, nos diz a professora Fagda, "o sentimento que tem que estar ali interligado na educação, não só na educação infantil [...] é o respeito pelo aquilo que você está fazendo [...]", é o respeito pela criança e o tempo dela.

Ou como acrescenta a professora Amires, "mas existe a parte boa, que é quando você vê elas avançando aprendendo mesmo", e esse aprender vai muito além dos códigos impostos pelas "cartilhas" da educação. Vivenciar a experiência é a base das descobertas da educação infantil. E fomentar esse prazer em descobrir é uma das ações de uma professora de crianças.

Nas relações com as crianças, quando nos deixamos afetar por elas, quando permitimos fazer passar as intensidades que as habitam, mudamos a maneira de olhar as crianças. Como diz a professora Heres, "você passa a ser mais observadora, você passa a observar, prestar mais atenção estar mais atenta as mudanças". Aprendemos, com as crianças a observar as miudezas do mundo, a habitar um tempo que não é somente o cronológico, mas o tempo âion, um tempo criança, no qual a intensidade e o acontecimento se apresentam, no presente. Olhar com olhos de outrem, como nos apresenta Freire (1989, p.68)

isso se verifica na prática em que o professor não se coloca como dono exclusivo do que sabe mas, pelo contrário, é através do que ele sabe que ele encaminha e sistematiza os dados observados na prática das crianças, para que elas próprias façam suas descobertas.

Por hora, parafraseando Madalena Freire, cabe entender que "essa caminhada foi especialmente bonita para mim porque pude sentir juntamente com as crianças uma emoção alegre carregada de afetividade [...]" (FREIRE, 1989, p.80). Junto a Freire, a professora Beres também se pronuncia...

[...] ser professora da Educação Infantil é dar oportunidade da criança ser criança, ela viver a sua infância de verdade no momento certo, do jeito certo, no tempo dela, é o tempo dela. Quando fala do ensino gradual para elas também, amadurecer na hora dela, ninguém vai apressar esse estágio, ninguém vai apressar esse momento, é deixar ela ser criança, [...]. Na creche ela é criança, porque na creche ela vai brincar, na creche ela vai ter outras crianças junto, além dela apreender, porque o professor também ensina, não só na parte da ludicidade, mas o ensino sistematizado oportuniza a criança a desenvolver a sua interação. (Professora Ebe). 
DOI: $10.12957 / \mathrm{e}-\mathrm{mosaicos} .2020 .42516$

\section{Algumas CONSIDERAÇões: "É MUITO RARO UM OCEANO SECAR 7"TAL COMO CONCLUIR UMA ESCRITA!}

O que podemos dizer depois de conversas hospitaleiras, acolhedoras, imbuídas de cumplicidade, confiança, respeito, dignidade e afetos com professoras da educação infantil? Conversas que emergiram do encontro entre professoras, pesquisadoras, crianças, imagens, sem caminhos rígidos a serem seguidos, sem fronteiras e muros que nos impediam de expor-nos, no movendo sempre rumo ao desconhecido. Então o que elas ainda nos apresentam? Podemos dizer, junto a elas, que tornar-se professora de criança não vem estabelecido em manual de instrução, ou em receitas médicas e de cozinha. Nem mesmo está escrito nas estrelas. Ou seja, não existe uma forma padrão, linear e supostamente infalível de exercer a docência com crianças. 0 que observamos, são movimentos intensos juntos a elas - as crianças - de aprender a ser professora, sendo professora, com um olhar sensível, uma escuta atenta, um corpo aberto à infância do mundo e a infância que atravessa as crianças.

Tornar-se professora na educação infantil traz consigo uma responsabilidade e uma sensibilidade que vai muito além do fazer docente. O caminho vai se desenhando diante dos olhos de quem se propõem trilhar por esse território profícuo da imaginação, da invenção, da criação, mantendo-se sempre aberta ao acontecimento e ao inesperado. Ser professora de educação infantil é aprender permanente com as crianças: é descobrir que a coruja, não mais é um animal que voa, mas uma bruxa, que seduz e encanta as crianças; é mexer na tampa do vento e destelhar o mundo, as nações, as fronteiras; é permanecer eminentemente alerta, sensível às coisas miúdas, ao que deixamos de ver, por não habitarmos mais a infância; é partilhar um sensível, um comum com as crianças no ver, no ouvir, no pegar, no provar, no cheirar; é abrirse a possibilidades de novas vivências, novas experiências, novas disposições não consensuais, sempre parciais e totalmente provisórias e lampejosas.

Esse tornar-se pode ser relacionado aqui a uma história contada pela professora Ebes durante uma de nossas conversas. A história narrada diz que uma lagarta desejava, em seu mais íntimo, aprender a voar. Ela via as borboletas com suas asas fininhas passeando por al", e queria, como elas, levantar voos rumo ao desconhecido. Buscando ajuda a lagarta ruma em realizar seu desejo: tornar-se o que não é. Ajudada por outros animais ela vai descobrindo pistas de como poderia tornar-se um animal que voa. Em dado momento, sem perceber, ela transforma-se em borboleta, e então pode voar.

É nesse ponto que professora e lagarta se encontram: tornar-se professora se conecta ao voo da não mais lagarta, mas no alçar de uma borboleta, na prática do próprio voar. Uma professora em devir, em vias de se tornar o que ainda não se é, só é possível se extrair partículas, como nos sugere Deleuze e Guattari (1997, p. 18), "entre as quais instauramos relações de movimento e repouso, de velocidade e

7 Esse subtítulo foi composto com fragmento retirado do livro O pequeno príncipe (SAINT-EXUPÉRY, 2015, p.52) 
DOI: $10.12957 / \mathrm{e}-\mathrm{mosaicos} .2020 .42516$

lentidão, as mais próximas daquilo que estamos em vias de nos tornarmos, e através das quais nos tornamos".

Além disso, a conversa possibilitou, ainda, conhecer o modo de trabalho do outro, o modo de pensar a educação infantil, e entender que as reflexões a partir das experiências partilhadas durante as conversas pode delinear caminhos de uma educação de qualidade, que respeita o espaço e o tempo da criança, que potencializa os meios e as ações dos que estão envolvidos em sala de aula, nos possibilitando estabelecer alguns caminhos que emergiram dos olhares das professoras de criança e de seus dizeres: educação infantil é o lugar de experimentação e sensações e percepções de quem é professora de criança. Indicando também que ouvir as professoras da infância, suas queixas, seus anseios, seus olhares, abre caminhos para uma temática bastante rara nos dias de hoje: a importância de ouvir, observar e dialogar com o universo da infância para compormos uma formação da escuta, uma pedagogia da escuta.

A conversa como uma opção estética, ética e política acontece no ver, no olhar, no ouvir, no estarmos atentos aquilo que muitas vezes nos passa despercebido, nos escapa aos olhos e aos ouvidos. Que possamos ver aquilo que não está diante dos olhos, que possamos ouvir o que não foi dito. Problematizar o próprio ato de fazer pesquisa nos permite pensar outras maneiras, inventar outros conceitos, outros mundos que possibilitem o exercício de outros pensamentos, um exercício diário da escuta do outro (das crianças, das professoras, de estudantes de tantos outros), para assim pensarmos outras maneiras de se fazer educação na universidade e nas instituições de educação para crianças pequenas, para os jovens e para os adultos.

\section{NOTA DOS AUTORES:}

Trabalho realizado com apoio do Programa Institucional de Iniciação Científica PIBIC/UNIR/CNPq Ciclo 2017/2018.

\section{REFERÊNCIAS}

AGAMBEN, G. Infância e História: destruição da experiência e origem da história. Belo Horizonte, MG: Editora UFMG, 2005.

DELEUZE, Gilles e GUATTARI, Felix. Mil platôs. Capitalismo e esquizofrenia. Vol 4. Rio de Janeiro: Editora 34, 1997.

FERNANDES, Claudia de O. HERMELINO, Laisa Bello. Infâncias e processos de escolarização. Rio de Janeiro: Grupo de Estudos e Pesquisa sobre Avaliação na Escola Pública/UFF, 2012.

FREIRE, Madalena - A Paixão de conhecer o mundo - Rio de Janeiro, Paz e Terra, 1989. 
DOI: $10.12957 / \mathrm{e}-\mathrm{mosaicos} .2020 .42516$

GAGNEBIN, Jeanne Marie. História e Narração em Walter Benjamin. São Paulo: Perspectiva, 2004.

GALLO, Sílvio. Infância e Poder: algumas interrogações à escola. In: KOHAN, Walter Omar (org.). Devir-criança da filosofia - Infância da Educação. Belo Horizonte, Autêntica, 2010.

HAWKING, Stephen. O Universo numa casca de noz. Rio de Janeiro: Intrínseca, 2016.

KOHAN, Walter. Ensaios de Filosofia e Educação In: Kohan Walter. Infância, estrangeiridade e ignorância. Belo Horizonte. MG: Autêntica, 2007.

ROCHA, Silvia Pimenta Velloso. Tornar-se quem se é: educação como formação, educação como transformação. In: Asociación Latinoamericana de Filosofia de La Educación, AC, v.3, 2015.

SAMPAIO, Carmen Sanches; RIBEIRO, Tiago; SOUZA, Rafael de. Conversa como metodologia de pesquisa: uma metodologia menos? IN: SAMPAIO, Carmen Sanches; RIBEIRO, Tiago; SOUZA, Rafael de. Conversa como metodologia de pesquisa: por que não?

SILVA, Lúcia Almeida da. SANTOS, Nair Iracema Silveira. Subjetividade e trabalho na educação. Fortaleza. CE: Rev. Mal-Estar Subj. vol.11 no.4, 2011.

Recebido em 06 de maio de 2019

Aceito em 12 de novembro de 2019

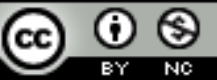

A e-Mosaicos Revista Multidisciplinar de Ensino, Pesquisa, Extensão e Cultura do Instituto de Aplicação Fernando Rodrigues da Silveira (CAp-UERJ) está disponibilizada sob uma Licença Creative Commons - Atribuição-NãoComercial 4.0 Internacional.

Os direitos autorais de todos os trabalhos publicados na revista pertencem ao(s) seu(s) autor(es) e coautor(es), com o direito de primeira publicação cedido à e-Mosaicos.

Os artigos publicados são de acesso público, de uso gratuito, com atribuição de autoria obrigatória, para aplicações de finalidade educacional e não-comercial, de acordo com o modelo de licenciamento Creative Commons adotado pela revista. 